\title{
Progressive Multifocal Leukoencephalopathy with Gray Matter Involvement
}

\author{
S. Ledoux, I. Libman, F. Robert and N. Just
}

\begin{abstract}
An unusual case of Progressive Multifocal Leukoencephalopathy (PML) in a Haitian mian with AIDS is reported. The lesions involving both white and gray matter are described radiologically and at post-mortem. The implications regarding neuroradiological differential diagnosis in AIDS as well as PML virulence in this type of patient are discussed.
\end{abstract}

RÉSUMÉ: Leuco-encéphalopathie multifocale progressive avec atteinte de la substance grise Nous rapportons un cas atypique de leuco-encéphalopathie progressive multifocale (LMP) survenue chez un patient haïtien victime du SIDA. Les lesions qui s'étendent à la fois au niveau des substances blanche et grise sont décrites. Nous commentons leurs aspects radiologiques et pathologiques ainsi que les implications d'une telle présentation concernant le diagnostic différentiel neuroradiologique et la virulence de l'agent causal de la LMP chez un tel type de patient.

Can.J. Neurol. Sci. 1989; 16: 200-202

Progressive multifocal leukoencephalopathy (PML), initially reported by Astrom et al in 1958,1 is an opportunistic infection caused by a DNA papovavirus that occurs in approximately $2 \%$ of the acquired immune deficiency syndrome (AIDS) population with neurological manifestations. ${ }^{2}$ We present the clinical, radiological and pathological features of an AIDS patient with PML. This patient illustrates unusually extensive gray matter involvement. The implications concerning radiological differential diagnosis in AIDS as well as JC Virus (JCV) virulence in a Human Immunodeficiency Virus (HIV) positive patient are discussed.

\section{Case Summary}

A 29-year-old Haitian male was admitted to hospital with a 3 week history of progressive right-sided weakness, gait disturbance and personality changes. On neurological examination, the patient was disoriented as to place, inattentive and echolalic. Cranial nerves were unremarkable. Motor examination revealed an intermittent right hemi-dystonic posture and a right arm drift. There was right-sided hyperreflexia but plantar responses were flexor bilaterally. Results of routine laboratory tests were unremarkable. The patient was anergic. Serology for toxoplasmosis, cytomegalovirus (CMV) $\operatorname{lgM}, \mathrm{Hbs} \mathrm{Ag}$ and VDRL were negative. Serology for HIV was positive. CSF studies were normal for cells and protein but IgGs were elevated $(12.8 \mathrm{mg} / \mathrm{dl})$ with positive oligoclonal banding. CT Scan with and without infusion revealed mild ventricular dilatation, a right nonenhancing hypodensity in the corona radiata and a portion of the superior thalamus, and equivocal hypodensities in the white matter of the centrum semiovale bilaterally (Figure 1a). Magnetic Resonance Imaging (MRI) performed two days later revealed multiple high-intensity signals located in the white matter but also in the gray matter, including the thalami and the left globus pallidus (Figure $1 \mathrm{~b}$ ). A diagnosis of AIDS was made and the patient was treated empirically for central nervous system (CNS) toxoplasmosis. His neurological status deteriorated over subsequent weeks and the patient died of a sepsis, 12 weeks after the onset of his disease.

The gross examination of the brain at post-mortem showed multiple demyelinating lesions, mostly subcortical and confluent, accompanied by extensive white matter destruction, more marked in the left hemisphere than the right. There was also involvement of both thalami, globus pallidus and internal capsule on the left. At the level of light microscopy, lesions had a similar pattern of distribution and were represented by multiple foci of myelin pallor associated with oligodendrocytes with enlarged nuclei containing ill-defined intranuclear inclusions. These cells were also found at the periphery of much larger demyelinating lesions, with reactive astrocytes which were enlarged and resembling neoplastic cells (Figure 2a). Electron microscopy revealed intranuclear orderly crystalline arrays of virus particles in oligodendrocytes. These appeared as spheroids, measuring approximately $40 \mathrm{~nm}$., characteristic for the polyoma group of papovavirus. No multinucleated cells or other inclusion bodies were present in the white matter.

\section{Discussion}

Our case of PLM exhibits a few interesting and unusual features. Movement disorders in AIDS patients have been attributed to toxoplasmosis, viral encephalitis, vacuolar myelopathy and CNS Whipple's disease. ${ }^{3}$ This patient had a right-sided intermittent dystonia as a result of a left basal ganglia lesion. ${ }^{4}$

The radiological presentation is also atypical. The usual CT hallmarks are the presence of low density lesions confined to the white matter, the lack of mass effect and the absence of contrast enhancement, distinguishing these lesions from tumours,

From the Department of Neurology, Pathology and Radiology, Jewish General Hospital, McGill University, Montreal

Received August 25, 1988. Accepted in final form January 17, 1989

Reprint requests to: Dr. Libman, Department of Neurology, Jewish General Hospital, 3755 Cote Ste-Catherine, Montreal, P.Q., Canada H3T IE2 


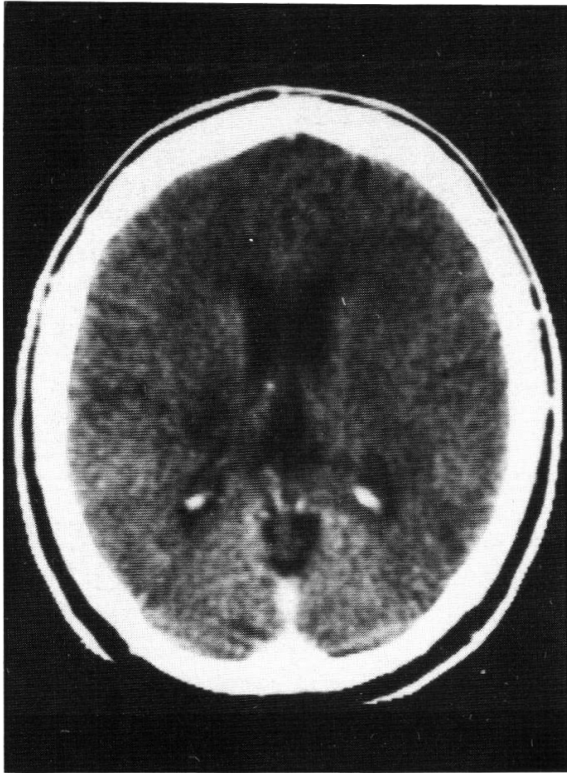

A

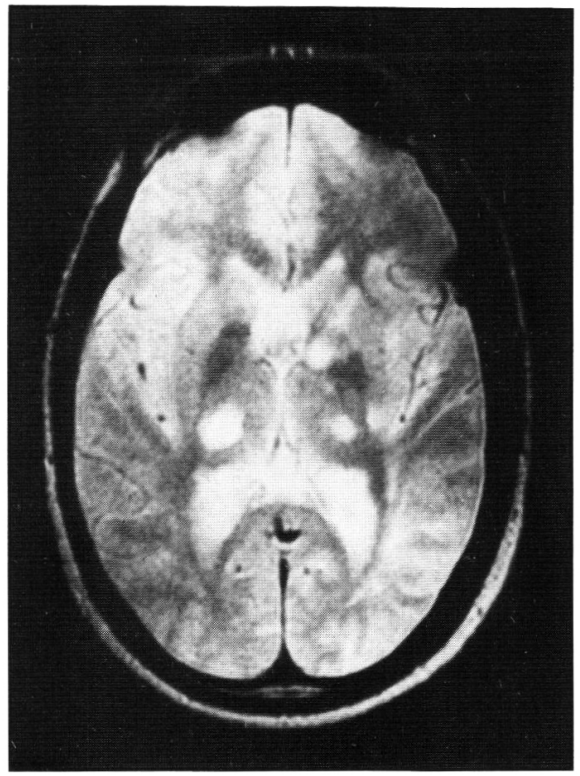

B

Figure la-CT of the head with contrast showing a nonenhancing hypodense lesion in the right corona radiara and superior thalamus, without any mass effect.

Figure lb - Magnetic resonance imaging slice obtained in the axial plane demonstrating lesions in the thalami, the left internal capsule and the left globus pallidus. However, the increased signals secn in the cortex and white matter of the right frontal and insular regions, as well as the left posterior temporal and occipital regions, could represent a shading artefact due to the specific type of coil used. The TR time is $2100 \mathrm{msec}$ and TE time is 60 msec.

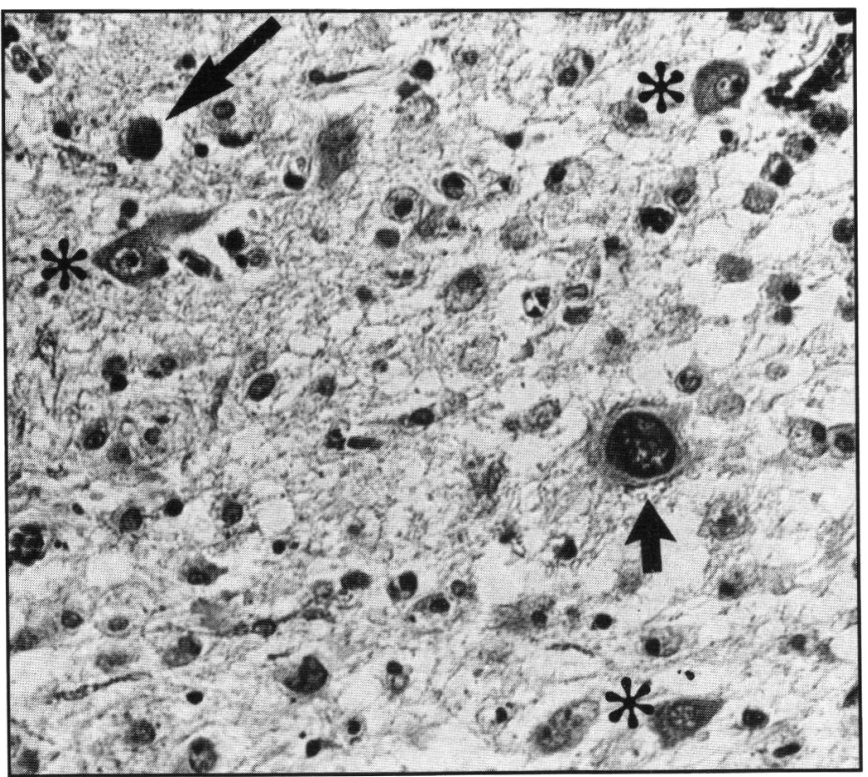

Figure 2 - Demyelinating lesion in the left globus pallidus. At the periphery of lesion containing numerous lipid-laden macrophages. there is an enlarged oligodendroglial nucleus with inclusions (long arrow). Short arrow points to an enlarged bizarre astrocyte with hyperchromatic nucleus. Nerve cells are marked by asterisks. (X100)

granulomas and other infections. ${ }^{5}$ Characteristic aspects seen with MRI include long $T_{1}$ and $T_{2}$ lesions limited to white matter, often asymetric and with no mass effect. ${ }^{6}$ However, in this patient, the PML lesions on MRI were diffuse in white and gray matter; the most significant extending into the left thalamus and globus pallidus. A recent case report of PML in a homosexual man with underlying Hodgkin's disease has shown a similar pattern of distribution. ${ }^{7}$ The atypical distribution of lesions with probable involvement of the myelinated axons within the striatum could perhaps be related to the observation that PML in
AIDS patients produces a more acute and severe brain infection, ${ }^{8}$ although this view has been challenged recently. ${ }^{9}$

MRI in PML appears in this case and in previous reports to be more sensitive and precise than CT in the detection and assessment of this disorder since it shows superior resolution between normal and abnormal white matter and gray matter. ${ }^{10}$ As a consequence, in AIDS patients presenting with focal neurological signs and whose CT Scans show lesions located in gray and white matter without contrast enhancement or mass effect, PML should be considered in the differential diagnosis. MRI is superior to CT Scanning in localizing those lesions which are most accessible to biopsy to confirm the diagnosis of PML in the AIDS population.

\section{REFERENCES}

1. Astrom KE, Mancall EL, Richardson EP Jr. Progressive multifocal leukoencephalopathy: A hitherto unrecognized complication of chronic lymphatic leukemia and Hodgkin's disease. Brain 1958; 81: 93-111.

2. Levy RM, Bredesen DE, Rosenblum ML. Neurological manifestations of the acquired immunodeficiency syndrome (AIDS): Experience at UCSF and review of the literature. J Neurosurg 1985; 62: 475-495.

3. Nath A, Jankovic J, Pettigrew LC. Movement disorders and AIDS Neurology 1987; 37: 37-41.

4. Grimes JD, Hassan MN, Quarrington AM, et al. Delayed-onset posthemiplegic dystonia: CT demonstration of basal ganglia pathology. Neurology 1982; 32: 1033-1035.

5. Caroll BA, Lane B, Norman D, et al. Diagnosis of progressive multifocal leukoencephalopathy by computed tomography. Radiology 1977; 122: 137-141.

6. Guilleux MH, Steiner RE, Young IR. MR imaging in progressive multifocal leukoencephalopathy. AJNR 1986; 7: 1033-1035.

7. Levy SD, Cottingham KL, Campbell RJ, et al. Progressive multifocal leukoencephalopathy and magnetic resonance imaging. Ann Neurol 1986: 19: 399-401.

8. Stoner GL, et al. JC papovavirus large tumour (T)-antigen expression in brain tissue of AIDS and non-AIDS patients with progressive multifocal leukoencephalopathy. Proc Natl Acad Sci USA 1986; 83: 227I-2275. 
9. Aksamit AJ, Gendelman HE, Gholam HP, et al. PML in AIDS: Comparison to non-AIDS cases by in situ hybridization and immunohistochemistry. Neurology 1987; 37 (Suppl 1): 345.
10. Donovan Post MJ, Sheldon JJ, Hensley GT, et al. Central nervous system disease in acquired immunodeficiency syndrome: Prospective correlation using CT, MR imaging and pathologic studies. Radiology 1986; 158: 141-148. 